\title{
Hambúrguer adicionado de pulmão bovino: elaboração, composição e avaliação
}

\section{sensorial}

\author{
Hamburger added with bovine lung: elaboration, composition and sensory evaluation \\ Hamburguesa con pulmón bovino: elaboración, composición y evaluación sensorial
}

Recebido: 25/05/2021 | Revisado: 01/06 /2021 | Aceito: 01/06/2021 | Publicado: 03/06/2021

\author{
Cristiane Nunes da Silva \\ ORCID: https://orcid.org/0000-0002-2477-3396 \\ Universidade Federal de Lavras, Brasil \\ E-mail: kristtiane2015@gmail.com \\ Juliana Rodrigues do Carmo \\ ORCID: https://orcid.org/0000-0002-9083-4863 \\ Universidade Federal de Lavras, Brasil \\ E-mail: juliana_docarmo@yahoo.com.br \\ Geane da Silva Oliveira \\ ORCID: https://orcid.org/0000-0002-6180-3195 \\ Instituto Federal Fluminense, Brasil \\ E-mail: geanee2017@gmail.com \\ Sheila Andrade Abrahão \\ ORCID: https://orcid.org/0000-0002-7551-9021 \\ Instituto Federal Fluminense, Brasil \\ E-mail: sheilanutri@yahoo.com.br
}

\begin{abstract}
Resumo
O pulmão bovino, considerado como víscera, muitas vezes é descartado de forma inadequada no meio ambiente. No entanto, este órgão destaca-se por apresentar elevados teores de ferro e proteínas com alto valor biológico. Diante disso, o objetivo do presente estudo foi elaborar um produto enriquecido com ferro heme biodisponível. Foram elaboradas formulações de hambúrguer com diferentes quantidades de pulmão bovino. Nestes produtos foram determinados a composição centesimal e o teor de ferro. As amostras foram avaliadas sensorialmente por testes de aceitação e de intenção de compra do produto. Os dados obtidos foram analisados por meio da análise de variância e comparados pelo teste de Tukey $(\mathrm{p}<0,05)$. Os hambúrgueres produzidos com diferentes quantidades de pulmão apresentaram majoritariamente em sua composição água (67,9-68,16\%), proteínas $(18,16-19,05 \%)$ e lipídios (8,09$8,31 \%$ ). O teor de ferro heme biodisponível variou entre 9,23 e 14,03 $\mathrm{mg} / 100 \mathrm{~g}$ entre as amostras, sendo aproximadamente três vezes maior na amostra com $100 \mathrm{~g}$ de pulmão, em relação à amostra controle. Os hambúrgueres formulados com adição de pulmão bovino foram aceitos pelos provadores (IA>70\%) e apresentaram altas porcentagens de intenção de compra $(>82 \%)$. O produto pode ser considerado uma alternativa promissora para a ingestão de ferro e de aminoácidos essenciais, que podem auxiliar no combate à anemia e reduzir as consequências causadas por esta carência no corpo humano, como déficit no desenvolvimento motor e cognitivo.
\end{abstract}

Palavras-chave: Subproduto bovino; Teor de ferro; Análise sensorial; Alternativa industrial.

\begin{abstract}
The bovine lung, considered as viscera, is often disposed of inappropriately in the environment. However, this organ stands out for having high levels of iron and proteins with high biological value. Therefore, the aim of the current study was to develop a product enriched with bioavailable heme iron. Hamburger formulations were prepared with different concentrations of bovine lung. In these products, the chemical composition and the iron content were determined. The samples were evaluated sensorially by affective acceptance test and purchase intention test. The data obtained were analyzed using analysis of variance and compared using the Tukey test $(\mathrm{p}<0.05)$. The hamburgers produced with different concentrations of lung presented mostly water (67.9-68.16\%), proteins (18.16-19.05\%) and lipids (8.09-8.31\%). The content of bioavailable heme iron varied between 9.23 and $14.03 \mathrm{mg} / 100 \mathrm{~g}$ in the samples, being approximately three times higher in the sample with $100 \mathrm{~g}$ of lung, compared to the control sample. Hamburgers formulated with the addition of bovine lung were accepted by the participants (AI> 70\%) and had high percentages of purchase intent $(>82 \%)$. The product can be considered a promising alternative for the intake of iron and essential aminoacids, which can help in the fight against anemia and reduce the consequences caused by this deficiency in the human body, such as a deficit in motor and cognitive development.
\end{abstract}

Keywords: Bovine by-product; Iron content; Sensory analysis; Industrial alternative. 


\begin{abstract}
Resumen
El pulmón bovino, considerado víscera, a menudo se desecha de forma inapropiada en el medio ambiente. Sin embargo, este órgano destaca por tener altos niveles de hierro y proteínas de alto valor biológico. Por tanto, el objetivo del presente estudio fue desarrollar un producto enriquecido con hierro hemo biodisponible. Se prepararon formulaciones de hamburguesa con diferentes concentraciones de pulmón bovino. En estos productos se determinó la composición química y el contenido de hierro. Las muestras fueron evaluadas sensorialmente mediante prueba afectiva de aceptación e intención de compra del producto. Los datos obtenidos se analizaron mediante análisis de varianza y se compararon mediante la prueba de Tukey $(\mathrm{p}<0,05)$. Las hamburguesas producidas con diferentes concentraciones de pulmón presentaron mayoritariamente agua $(67,9-68,16 \%)$, proteínas $(18,16-19,05 \%)$ y lípidos $(8,09-8,31 \%)$. El contenido de hierro hemo biodisponible varió entre 9,23 y $14,03 \mathrm{mg} / 100 \mathrm{~g}$ entre muestras, siendo aproximadamente tres veces mayor en la muestra con $100 \mathrm{~g}$ de pulmón, en comparación con la muestra control. Las hamburguesas formuladas con la adición de pulmón bovino fueron aceptadas por los catadores (IA>70\%) y tuvieron altos porcentajes de intención de compra $(>82 \%)$. El producto puede considerarse una alternativa prometedora para la ingesta de hierro y aminoácidos esenciales, que pueden ayudar a combatir la anemia y reducir las consecuencias que provoca esta deficiencia en el cuerpo humano, como el déficit en el desarrollo motor y cognitivo.
\end{abstract}

Palabras clave: Subproducto bovino; Contenido de hierro; Análisis sensorial; Alternativa industrial.

\title{
1. Introdução
}

De acordo com a Organização Mundial da Saúde (OMS), a anemia é definida como "um estado em que a concentração de hemoglobina do sangue é baixa em consequência da carência de um ou mais nutrientes essenciais". Neste contexto, a anemia por deficiência de ferro ou anemia ferropriva é o balanço negativo entre a quantidade de ferro disponível e a necessidade orgânica do organismo (Bezerra et al., 2018; OMS, 1975).

O ferro é um micronutriente essencial durante a fase de crescimento e desenvolvimento da criança e do adolescente (Harika et al., 2017; Lynch et al., 2018), pois este atua na formação da hemoglobina, no sistema imunológico, na síntese do DNA, no transporte de oxigênio e no fornecimento de energia (Camaschella, 2017; Wong, 2017). A deficiência deste nutriente pode causar inúmeros problemas na saúde, como baixa oxigenação do sangue, baixo peso, alterações gastrointestinais e na função cerebral, redução na função imunitária, no trabalho físico, mental e no desenvolvimento psicológico e cognitivo (Silva et al., 2015).

A anemia é considerada um problema de saúde pública, que está associado com fatores determinantes, múltiplos e complexos, que interagem para o seu desenvolvimento, como: condições socioeconômicas, baixo nível educacional, dieta alimentar, estado nutricional e doenças infecciosas parasitárias (Vieira et al., 2017). De forma a diminuir a prevalência desta carência nutricional, foi observado que a fortificação dos alimentos tem sido uma boa alternativa (Chadare et al., 2019; Vieira et al., 2017). Este método apresenta alta efetividade, pois não implica em medicações nos hábitos alimentares das crianças, sendo adicionadas pequenas quantidades de alimentos com grande biodisponibilidade de ferro em sua composição (Silva et al., 2015).

O hambúrguer é um produto cárneo industrializado, obtido por meio da carne moída, com adição ou não de tecido adiposo e ingredientes, moldado e submetido ao processo tecnológico adequado, devendo a textura, cor, sabor e odor serem característicos (Brasil, 2000). No Brasil, o hambúrguer se tornou popularmente consumido por todas classes sociais ao longo dos últimos anos, principalmente pelas características sensoriais atrativas, preço, conveniência e praticidade. Isso deve as modificações no perfil dos consumidores brasileiros, interligado, com aumento no consumo das refeições fora de domicílio (Rocha et al., 2019).

O pulmão bovino é um subproduto bastante desperdiçado nos abatedouros brasileiros, devido as suas características sensoriais. Apesar da baixa aceitabilidade pelos consumidores, este subproduto tem se destacado por ser fonte de ferro e conter proteínas com alto valor biológico, tornando-se uma importante alternativa na fortificação dos alimentos para o combate à anemia ferropriva (Jayathilakan et al., 2012). O ferro presente no pulmão possui maior biodisponibilidade, pois os produtos de origem animal fornecem em torno de $50 \%$ de ferro na forma heme, que participa com a hemoglobina na formação dos 
aminoácidos, produção de colágeno, atuam no sistema imunológico e no crescimento e desenvolvimento da criança. Estudos foram realizados utilizando o pulmão bovino para a fortificação de outros alimentos, como, snacks, salgadinhos e biscoitos (Hoffmann \& Kruger, 2011).

São crescentes as exigências dos consumidores por produtos saudáveis, seguros e inovadores, tornando o mercado competitivo. Isso tem feito com que as indústrias invistam no desenvolvimento de novos produtos. Neste contexto, o uso da análise sensorial tem sido uma ferramenta eficaz para o desenvolvimento e introdução dos novos produtos no mercado (Grützmann et al., 2019; Magalhães \& Cazal, 2021). Este método através do envolvimento dos consumidores, e, da relação entre as tecnologias e as estratégias de mercado, permite avaliar a aceitabilidade do produto, melhorar a qualidade, conhecer as expectativas e as reações dos consumidores aos novos produtos desenvolvidos (Carmo et al., 2019). Portanto, a análise sensorial é uma parte significativa para que o produto atenda às necessidades dos consumidores e para garantir o sucesso em sua comercialização (Lima Segundo et al., 2021).

Diante disso, o objetivo deste trabalho foi elaborar um hambúrguer adicionado de um subproduto bovino (pulmão), bem como avaliar as propriedades físico-químicas e sensoriais deste produto, a fim de possibilitar uma nova alternativa de consumo, aproveitamento e agregação de valor à uma das partes menos nobres do boi.

\section{Metodologia}

\subsection{Formulação dos hambúrgueres}

Os pulmões bovinos foram coletados no Abatedouro Municipal da cidade de Bom Jesus do Itabapoana/RJ com registro do Serviço de Inspeção Municipal (SIM). O hambúrguer foi elaborado no Setor de Carnes e Derivados do Instituto Federal Fluminense - Campus Bom Jesus do Itabapoana/RJ. As formulações foram elaboradas de acordo com o regulamento técnico de identidade e qualidade de hambúrguer (Brasil, 2000), de atribuição à função dos aditivos e seus limites máximos para o uso em carnes e produtos cárneos, ao conteúdo de nutrientes e informações nutricionais complementares (Brasil, 1998). Além disso, durante o preparo dos produtos foram adotas as Boas Práticas de Fabricação de acordo com a legislação vigente (Brasil, 2002).

Primeiramente, a carne bovina e o toucinho foram moídos no disco mais fino do moedor (5 a $6 \mathrm{~mm})$, até a formação de uma pasta. O pulmão foi moído em liquidificador industrial para adição nas formulações. Após esses processos, em um recipiente de aço inox foram adicionados: carne, toucinho, pulmão bovino, água com gelo, proteína texturizada de soja, farinha de trigo, sal refinado, emulsificante, antioxidante, creme de cebola, alho e pimenta do reino, misturando-se até obter uma completa homogeneização e absorção dos ingredientes pela massa. Na Tabela 1 estão expressos os ingredientes que foram utilizados para a elaboração das três formulações de hambúrgueres. Cada formulação foi dividida em porções de aproximadamente $50 \mathrm{~g}$, as quais foram acondicionados em embalagens plásticas e armazenadas em câmaras de congelamento à temperatura de $-18^{\circ} \mathrm{C}$, para determinação das análises seguintes. 
Tabela 1 - Ingredientes utilizados na formulação dos hambúrgueres com e sem adição de pulmão bovino.

\begin{tabular}{|c|c|c|c|}
\hline \multirow[t]{2}{*}{ Ingredientes } & \multicolumn{3}{|c|}{ Formulação } \\
\hline & $\mathbf{C}^{*}$ & F1* & F2 $^{*}$ \\
\hline Carne bovina magra (Acém) $(\mathrm{g})$ & 500 & 450 & 400 \\
\hline Toucinho suíno gordo (g) & 165 & 165 & 165 \\
\hline Pulmão bovino (g) & - & 50 & 100 \\
\hline Água/gelo (mL) & 165 & 165 & 165 \\
\hline Proteína texturizada de soja (g) & 50 & 50 & 50 \\
\hline Farinha de trigo $(\mathrm{g})$ & 33 & 33 & 33 \\
\hline Sal refinado $(\mathrm{g})$ & 33 & 33 & 33 \\
\hline Emulsificante (g) & 8 & 8 & 8 \\
\hline Antioxidante (g) & 2 & 2 & 2 \\
\hline Creme de cebola $(\mathrm{g})$ & 2 & 2 & 2 \\
\hline Alho (g) & 2 & 2 & 2 \\
\hline Pimenta do reino $(\mathrm{g})$ & 1 & 1 & 1 \\
\hline
\end{tabular}

*C - Controle (sem pulmão), F1 - Formulação 1 (50 g de pulmão), F2 - Formulação 2 (100 g de pulmão).

Fonte: Dados da Pesquisa.

\subsection{Determinações físico-químicas}

A atividade de água $\left(\mathrm{a}_{\mathrm{w}}\right)$ foi determinada em termohigrômetro digital (Decagon, Aqualab Series 4TE, Pullman, USA) e o pH foi determinado com o auxílio de pHmetro digital (Modelo DM 20, Digimed), ambos de acordo com as normas do Instituto Adolfo Lutz (IAL, 2008). Na determinação da cor foi utilizado o colorímetro HunterLab (modelo Minolta CR 400, Osaka, Japão), para a obtenção dos seguintes parâmetros, luminosidade $\left(L^{*}\right)$ e as coordenadas de cromaticidade $\left(a^{*}, b^{*}\right)$.

\subsection{Composição centesimal}

A determinação de umidade, proteínas, lipídios, cinzas e carboidratos foi realizada de acordo com as normas do Instituto Adolfo Lutz (IAL, 2008). O valor energético foi calculado de acordo com os fatores gerais de conversão de Atwater: valor energético total $(\mathrm{kcal} / 100 \mathrm{~g})=(\%$ proteínas $\mathrm{x} 4 \mathrm{kcal} / \mathrm{g})+(\%$ lipídios $\mathrm{x} 9 \mathrm{kcal} / \mathrm{g})+(\%$ carboidratos x $4 \mathrm{kcal} / \mathrm{g})$ (FAO/WHO, 2002).

\subsection{Análise de ferro}

As amostras foram mineralizadas por via úmida à $110^{\circ} \mathrm{C}$ por 2 horas no bloco digestor, e introduzidos no nebulizador para a determinação do teor de ferro pelo método de espectrometria de absorção atômica de chama (Agilent Technologies Modelo 240), com lâmpada de cátodo para a determinação do ferro com comprimento de onda 248,3 nm, com chama de ar (2,5 $\mathrm{L} / \mathrm{h}$ ) e acetileno $(10 \mathrm{~L} / \mathrm{h})$ sob a temperatura de $2000^{\circ} \mathrm{C}$, no Laboratório de Análises de Solos da Universidade Federal de Viçosa $-\mathrm{UFV} / \mathrm{MG}$. 


\subsection{Análise sensorial}

Para a realização da análise sensorial, os hambúrgueres foram grelhados em chapa aquecida a $150^{\circ} \mathrm{C}$ por 6 minutos na Cozinha Experimental do Instituto Federal Fluminense - Campus Bom Jesus do Itabapoana/RJ. A análise foi realizada com 50 provadores não treinados (alunos, funcionários e professores), com idade acima de 18 anos do Instituto Federal Fluminense e consumidores de hambúrguer. Cada provador recebeu 3 amostras codificadas e randomizadas de hambúrgueres (100 g) à temperatura ambiente $\left(27^{\circ} \mathrm{C}\right)$ em uma cabine individual equipada com luz branca (Laboratório de Análise Sensorial). Foram avaliados os seguintes atributos sensoriais: sabor, cor, textura e impressão global das três formulações. A avaliação foi realizada por meio de uma ficha de avaliação contendo uma escala hedônica mista estruturada de 7 pontos, na qual o extremo 1 correspondente a "desgostei muitíssimo" e o extremo 7 a "gostei muitíssimo". Também foi avaliada a intenção de compra através da escala hedônica de 1 a 5 pontos, na qual o extremo corresponde a "certamente compraria" e o extremo 5 a “certamente não compraria (Minim, 2013).

O índice de aceitabilidade (IA) para os atributos avaliados em cada formulação foi calculado segundo Minim (2013) (Equação 1).

$$
\mathrm{IA}(\%)=\frac{\mathrm{A}_{\mathrm{m}} \times 100}{\mathrm{~B}}
$$

onde, $\mathrm{A}_{\mathrm{m}}$ = valor médio da pontuação obtida para cada atributo do hambúrguer e $\mathrm{B}$ = pontuação máxima em que o produto pode ser avaliado (pontuação 7 no teste de aceitação e pontuação 5 no teste de intenção de compra).

\subsection{Análise estatística}

Os resultados das análises caracterização e análise sensorial para amostra C (controle), F1 (50 g de pulmão) e F2 (100 $\mathrm{g}$ de pulmão) foram submetidos à análise de variância (ANOVA) e comparados pelo teste de médias de Tukey à $5 \%$ de significância, através do software Sisvar ${ }^{\mathrm{R}}$.

\section{Resultados e Discussão}

\subsection{Determinações físico-químicas}

De acordo com Tabela 2, as formulações 1 e 2, não diferiram estatisticamente ( $\mathrm{p}<0,05)$, demonstrando que a adição de diferentes quantidades de pulmão bovino (50 e $100 \mathrm{~g}$ ) não contribuiu para o aumento da $\mathrm{a}_{\mathrm{w}}$ dos hambúrgueres. No entanto, os mesmos requerem cuidado no seu armazenamento por apresentarem $a_{w}\left(a_{w}>0,9\right)$. Com base nos valores de pH observou-se diferenças significativas $(\mathrm{p}<0,05)$ para a F2 e F1 em relação às amostras controle. Esta ligeira diferença pode ser devido ao pulmão apresentar um $\mathrm{pH}$ de 6,28, próximo a neutralidade, enquanto que, a amostra controle possui maior quantidade de acém que tem um pH em torno de 5,96 (Damasceno et al, 2013; Rolim, 2015). Contudo, as F1 e F2 se encontram dentro dos limites da legislação (5,4-6,4) (Brasil, 1997), que indica que a carne está aceitável para o consumo. Paula et al. (2019), observou valores inferiores em relação a atividade de água $(0,8$ a 0,9$)$ e superiores para o $\mathrm{pH}(6,3$ a 6,4$)$, ao adicionar sementes de chia como substituto de gordura à massa de hambúrguer bovino. 
Tabela 2 - Valores médios da atividade de água e pH do hambúrguer sem e com diferentes quantidades de pulmão bovino.

\begin{tabular}{|c|c|c|c|}
\hline Parâmetros & & Amostras & \\
\hline \multirow[b]{2}{*}{ Atividade de água } & $\mathbf{C}^{*}$ & F1 $^{*}$ & F2* \\
\hline & $0,919 \pm 0,02^{\mathrm{a}}$ & $0,919 \pm 0,05^{\mathrm{a}}$ & $0,916 \pm 0,02^{a}$ \\
\hline $\mathbf{P h}$ & $6,03 \pm 0,000^{b}$ & $6,06 \pm 0,001^{b}$ & $6,10 \pm 0,002^{a}$ \\
\hline
\end{tabular}

${ }^{*} \mathrm{C}$ - Controle (sem pulmão), F1 - Formulação 1 (50 g de pulmão), F2 - Formulação 2 (100 g de pulmão). Letras na mesma linha não diferem estatisticamente entre si pelo Teste de Tukey a 5\% de significância $(\mathrm{p}<0,05)$.

Fonte: Dados da Pesquisa.

Em relação ao parâmetro $L^{*}$ (luminosidade), em que 0 indica a cor preta, e 100, a cor branca, os resultados mostraram diferenças significativas $(\mathrm{p}<0,05)$ entre as formulações avaliadas (Tabela 3). As amostras F1 e F2 apresentaram menor luminosidade em comparação com a amostra controle, devido a adição pulmão bovino. Para o parâmetro $a^{*}$, que varia do $a+$ para o vermelho e $a$ - para o verde, as formulações F1 e F2 também diferiram significativamente $($ p $<0,05)$ da amostra controle, pela adição do pulmão bovino, o qual que promoveu uma maior intensificação na coloração vermelha. A coloração vermelha é majoritária nos produtos cárneos e seus subprodutos, com isso ao adicionar o pulmão bovino a massa do hambúrguer, esperase uma maior concentração dessa coloração, devido à alta concentração de hemoglobina, mioglobina, citocromo e outros constituintes presentes no pulmão (Suman \& Joseph, 2013; Yu et al., 2017).

Os resultados encontrados para o parâmetro $b^{*}$, que varia $b+$ para o amarelo e $b$ - para o azul, mostraram que houve diferenças significativas $(\mathrm{p}<0,05)$ (Tabela 3) entre as amostras. A amostra F2, apresentou menor tendência à coloração amarelada. Fernandes \& Pizato (2019), encontraram nas formulações de hambúrgueres bovino com diferentes quantidades de farinha de sorgo, uma redução significativa para a $L^{*}\left(50,33\right.$ a 42,74). Os parâmetros $a^{*}(7,03$ a 8,25$)$ e $b^{*}(14,80$ a 12,02$)$, também demonstraram diferenças entre si, porém, estes valores foram superiores aos encontrados neste estudo para a $L^{*}$ e $b^{*}$ e inferiores ao parâmetro $a^{*}$.

Tabela 3 - Valores médios da avaliação colorimétrica dos hambúrgueres sem e com adição de pulmão bovino.

\begin{tabular}{cccc}
\hline & \multicolumn{3}{c}{ Amostras } \\
\cline { 2 - 4 } Parâmetros & $\mathbf{C}^{*}$ & F1 $^{*}$ & F2 $^{*}$ \\
\hline $\boldsymbol{L}^{*}$ & $45,43 \pm 1,39^{\mathrm{a}}$ & $37,57 \pm 0,87^{\mathrm{b}}$ & $35,30 \pm 0,40^{\mathrm{b}}$ \\
$\boldsymbol{a}^{*}$ & $8,18 \pm 0,93^{\mathrm{b}}$ & $11,25 \pm 0,55^{\mathrm{a}}$ & $11,63 \pm 0,94^{\mathrm{a}}$ \\
$\boldsymbol{b}^{*}$ & $10,43 \pm 1,17^{\mathrm{a}}$ & $8,70 \pm 0,20^{\mathrm{ab}}$ & $7,37 \pm 0,80^{\mathrm{b}}$ \\
\hline
\end{tabular}

*C - Controle (sem pulmão), F1 - Formulação 1 (50 g de pulmão), F2 - Formulação 2 (100 g de pulmão). Letras iguais na mesma linha, não diferem estatisticamente entre si pelo Teste de Tukey a 5\% de significância $(\mathrm{p}<0,05)$.

Fonte: Dados da Pesquisa.

\subsection{Composição centesimal}

Com base nos resultados da Tabela 4, a formulação F1 e F2 apresentaram diferenças significativas (p<0,05), nos teores de umidade em relação com a amostra controle. $\mathrm{O}$ aumento no teor de umidade pode estar relacionado com a adição de pulmão bovino à massa do hambúrguer, que apresenta alto percentual de água em sua composição (78,46\%) (Damasceno et al. 2013), com valor superior ao acém bovino (72,7 g/100 g) (TACO, 2011). Os valores encontrados estão de acordo com a Tabela 
TACO (2011) para carne de hambúrguer (63,6\%). Fernandes e Pizato (2019), encontraram resultados superiores ao do presente estudo para o teor de umidade $(70,32-70,74 \%)$, em formulações de hambúrguer bovino com diferentes quantidades de farinha de sorgo.

Tabela 4 - Composição centesimal do hambúrguer sem e com diferentes quantidades de pulmão bovino.

\begin{tabular}{cccc}
\hline \multirow{2}{*}{ Composição Centesimal (\%) } & \multicolumn{3}{c}{ Amostras } \\
\cline { 2 - 4 } & $\mathbf{C}^{*}$ & $\mathbf{F 1}^{*}$ & F2 $^{*}$ \\
\hline Umidade & $65,06 \pm 0,73^{\mathrm{b}}$ & $67,29 \pm 0,03^{\mathrm{a}}$ & $68,16 \pm 0,32^{\mathrm{a}}$ \\
Proteínas & $19,25 \pm 0,59^{\mathrm{a}}$ & $18,16 \pm 0,47^{\mathrm{a}}$ & $19,05 \pm 0,23^{\mathrm{a}}$ \\
Lipídios & $7,46 \pm 0,61^{\mathrm{a}}$ & $8,31 \pm 0,22^{\mathrm{a}}$ & $8,09 \pm 0,32^{\mathrm{a}}$ \\
Cinzas & $2,77 \pm 0,06^{\mathrm{a}}$ & $2,50 \pm 0,11^{\mathrm{b}}$ & $2,30 \pm 0,36^{\mathrm{b}}$ \\
Carboidratos & $5,45 \pm 1,89^{\mathrm{a}}$ & $3,73 \pm 0,50^{\mathrm{ab}}$ & $2,01 \pm 0,36^{\mathrm{b}}$ \\
\hline Valor calórico (kcal/100g) & $165,95 \pm 0,20^{\mathrm{a}}$ & $162,38 \pm 1,00^{\mathrm{a}}$ & $158,25 \pm 4,70^{\mathrm{a}}$
\end{tabular}

${ }^{*} \mathrm{C}$ - Controle (sem pulmão), F1 - Formulação 1 (50 g de pulmão), F2 - Formulação 2 (100 g de pulmão). Letras iguais na mesma linha não diferem estatisticamente entre si pelo Teste de Tukey a 5\% de significância $(\mathrm{p}<0,05)$.

Fonte: Dados da Pesquisa.

As principais fontes de proteínas presentes no hambúrguer elaborado neste estudo são a carne bovina, o pulmão e a proteína de soja texturizada. A carne e o pulmão bovino, possuem proteínas com alto valor biológico e aminoácidos essenciais, sendo a carne, a principal fonte de obtenção deste nutriente na dieta alimentar do ser humano (Pasiakos et al., 2015; Selmane et al. 2008; Wyness, 2016), enquanto, que a proteína texturizada de soja também é uma fonte proteica de origem vegetal, por apresentar 40\% de proteínas e aminoácidos com boa biodisponibilidade (Arueya et al., 2017; Feiner, 2016). Entretanto, não houve aumento significativo de proteínas $(\mathrm{p}<0,05)$ entre as F1 e F2 em comparação com a amostra C. Os valores encontrados nas formulações podem estar relacionados com a substituição da carne bovina, por pulmão. A substituição não proporcionou o aumento no teor de proteínas, pois os dois ingredientes são fontes similares, apresentando altas concentrações deste nutriente em sua composição e menor diferença entre a proporção (TACO, 2011, Damasceno et al. 2013). Apesar de não ter apresentado aumento no teor de proteínas com à adição de diferentes quantidades de pulmão, o hambúrguer pode ser considerado um alimento rico em proteínas e aminoácidos essenciais (Moreira-Araújo et al., 2008). Rocha et al. (2019), encontraram valores inferiores de proteínas $(16,0-16,9 \mathrm{~g} / 100)$ para um produto tipo hambúrguer adicionado com diferentes quantidades de fígado bovino e aveia.

As formulações analisadas não apresentaram diferenças estatisticamente significativas ( $p>0,05)$ em relação ao teor de lipídios. Embora, houvesse uma adição de diferentes quantidades de pulmão, esta não contribuiu para o aumento no teor de lipídios nos hambúrgueres (Tabela 4). Os resultados encontrados podem ser devido ao fato de o pulmão ter menor teor de lipídios $(2,5 \mathrm{~g} / 100 \mathrm{~g})$ em relação ao acém $(5,9 \mathrm{~g} / 100 \mathrm{~g})$, que é a única fração bovina na formulação controle (Institute of Medicine, 2001; TACO, 2011). Em seus estudos com adição de ingredientes funcionais à massa do hambúrguer bovino, BisSouza et al. (2018) observaram um percentual de lipídios inferior ao do presente estudo (6,07-7,8\%).

Os teores de cinzas das formulações F1 e F2 apresentaram valores ligeiramente menores em comparação com a amostra controle ( $p>0,05)$. Este comportamento pode ser devido ao pulmão não apresentar valores significativos de resíduos minerais fixos em sua composição $(1,13 \mathrm{~g} / 100 \mathrm{~g})$ (Damasceno et al., 2013). Os valores deste estudo foram semelhantes ao 
encontrado por Rocha et al. (2019), que obtiveram de 2,55 a 2,59 g/100 g para um produto tipo hambúrguer adicionado com diferentes quantidades de fígado bovino e aveia.

O conteúdo de carboidratos apresentou diferença estatisticamente significativa para F2 em comparação com a amostra controle ( $p>0,05$ ), que pode estar relacionado com a baixa concentração de carboidratos presentes na composição do pulmão, visto que os produtos cárneos e seus subprodutos não são fonte deste nutriente (TACO, 2011). Rocha et al. (2019), obtiveram maiores teores de carboidratos ( 9,22 a 13,34 g/100 g), comparados ao do presente estudo, uma vez que adicionar diferentes quantidades de fígado bovino e aveia (fibra solúvel) em um produto tipo hambúrguer.

A adição de $100 \mathrm{~g}$ de pulmão bovino à massa do hambúrguer (F2), contribuiu para menor valor calórico do hambúrguer, o que pode estar associado à composição do pulmão, que apresenta baixo teor de lipídios (2,5 g/100 g) (Institute of Medicine, 2001). Valores próximos ao do estudo foram encontrados por Hautrive et al. (2019), em hambúrguer de carne bovina com adição de quitosana e farinha de linhaça dourada para a reposição de gordura (141,8-158,62 kcal).

De maneira geral, observou-se que a água, as proteínas e os lipídios foram os constituintes majoritários dos produtos. As formulações apresentaram-se dentro dos limites estabelecidos pela legislação brasileira vigente, que determina que os hambúrgueres devem conter o percentual mínimo de $15 \%$ de proteínas, máximo de $23 \%$ de lipídios, $3 \%$ de cinzas, e em torno de $3 \%$ de carboidratos totais (Brasil, 2000).

\subsection{Teor de ferro}

Como pode ser observado na Tabela 5, os resultados para o ferro das amostras diferiram significativamente entre si $(\mathrm{p}<0,05)$. As formulações F1 e F2 com apresentaram aumento no teor de ferro em comparação com amostra controle, sendo aproximadamente três vezes maior na amostra F2 em relação à amostra controle.

Tabela 5 - Valores médios do teor de ferro nas formulações com diferentes quantidades de pulmão bovino e sem adição.

\begin{tabular}{l} 
Ferro (mg/100g) \\
\cline { 2 - 3 } \\
\cline { 2 - 3 }
\end{tabular}

A recomendação diária de ferro para crianças entre 4 e 8 anos é $10 \mathrm{mg}$, e para as crianças entre 9 a 13 anos é de $8 \mathrm{mg}$ (Institute of Medicine, 2001) sendo assim, os hambúrgueres com adição de pulmão (F1 e F2) forneceriam teores de ferro superiores a 92\%, como recomendado pela legislação, para atender as necessidades diárias de crianças e adolescentes. Hoffmann e Kruger (2011), encontraram 9,27 mg/100 g de ferro em biscoito enriquecido com farinha de pulmão (8\%), com boa aceitação pelo público infantil. Moreira-Araújo et al.(2008), reportaram que ao adicionar pulmão bovino e grão de bico ao snacks de milho, obtiveram $9,2 \mathrm{mg} / 100 \mathrm{~g}$ de ferro, evidenciando uma redução de $61,5 \%$ para $11,5 \%$ na incidência da anemia.

\subsection{Análise sensorial}

Os valores médios de aceitação dos atributos textura, cor, sabor e impressão global dos hambúrgueres formulados com a adição de pulmão bovino em diferentes quantidades, estão expressos na Tabela 6. Os resultados mostraram médias de nota 5-6, correspondente ao "gostei ligeiramente" e "gostei moderadamente" na escala hedônica. A adição de diferentes 
quantidades de pulmão bovino (50 e $100 \mathrm{~g}$ ) nas formulações não influenciou significativamente $(\mathrm{p}<0,05)$ nas notas dos provadores quanto aos atributos avaliados em comparação com a amostra controle.

Tabela 6 - Aceitação média e índice de aceitabilidade para os atributos das formulações de hambúrgueres.

\begin{tabular}{cccc}
\hline Atributos & \multicolumn{3}{c}{ Amostras } \\
\cline { 2 - 4 } sensoriais & $\mathbf{C}^{*}$ & $\mathbf{F 1}^{*}$ & F2 $^{*}$ \\
\hline Sabor & $5,84 \pm 1,22^{\text {a }}$ & $5,57 \pm 1,31^{\text {a }}$ & $5,63 \pm 1,09^{\text {a }}$ \\
& $(83,47 \pm 17,47)$ & $(79,51 \pm 18,69)$ & $(80,49 \pm 15,50)$ \\
Cor & $5,08 \pm 1,68^{\text {a }}$ & $5,04 \pm 1,41^{\text {a }}$ & $5,31 \pm 1,31^{\text {a }}$ \\
& $(72,55 \pm 24,05)$ & $(71,97 \pm 20,20)$ & $(75,82 \pm 18,67)$ \\
Textura & $5,47 \pm 1,46^{\text {a }}$ & $5,28 \pm 1,38^{\text {a }}$ & $5,51 \pm 1,29^{\text {a }}$ \\
& $(78,15 \pm 20,87)$ & $(75,47 \pm 19,69)$ & $(78,71 \pm 18,38)$ \\
Impressão & $5,51 \pm 1,30^{\text {a }}$ & $5,38 \pm 1,23^{\text {a }}$ & $5,48 \pm 1,29^{\text {a }}$ \\
Global & $(78,71 \pm 18,60)$ & $(76,82 \pm 17,55)$ & $(78,31 \pm 18,44)$ \\
\hline
\end{tabular}

${ }^{*} \mathrm{C}$ - Controle (sem pulmão), F1 - Formulação 1 (50 g de pulmão), F2 - Formulação 2 (100 g de pulmão). Letras iguais na mesma linha não diferem estatisticamente entre si pelo Teste de Tukey a $5 \%$ de significância $(\mathrm{p}<0,05)$.

Fonte: Dados da Pesquisa.

No presente estudo, todas as formulações de hambúrguer foram consideradas aceitas, pois apresentaram índices de aceitabilidade superiores a 70\% (Minim, 2013). Embora os valores médios de aceitação, para os diferentes atributos, não tenham apresentado diferenças significativas $(\mathrm{p}<0,05)$ (Tabela 6), para os hambúrgueres elaborados, os índices de aceitação para todos os atributos avaliados, foram ligeiramente maiores para a formulação com $100 \mathrm{~g}$ de pulmão (F2). Hoffmann e Kruger (2011), por sua vez, encontraram uma menor aceitação para o biscoito com adição de $40 \mathrm{~g}$ de farinha de pulmão bovino. O mesmo foi observado por Sobrinho et al. (2009), em hambúrguer adicionado com 40\% de vísceras (coração e fígado). Em ambos os casos, os produtos que apresentaram maiores quantidades de pulmão, coração é fígado obtiveram menores índices de aceitação.

De maneira geral, os resultados mostraram que a adição do pulmão nas quantidades de 50 e $100 \mathrm{~g}$ não modificam as características sensoriais do produto. Este resultado é considerado positivo para um produto com adição de um subproduto, demostrando, que além de não causar mudanças perceptíveis nas características sensoriais, é uma ótima alternativa para melhorar a qualidade nutricional do hambúrguer. Portanto, a adição de pulmão à massa do hambúrguer não é um obstáculo para a aceitabilidade deste produto pelos consumidores, pelo contrário, é uma forma de inovação e agregação de valor, tornando o subproduto cárneo descartado pelos abatedouros, em uma matéria-prima que pode ser aplicada no processamento dos alimentos e no desenvolvimento de novos produtos.

A investigação de intenção de compra (soma de "certamente compraria", "provavelmente compraria" e "talvez compraria") para os hambúrgueres produzidos mostrou altas porcentagens, sendo $86 \%, 88 \%$ e $82 \%$ para as formulações controle, F1 e F2, respectivamente (Figura 1). Estes resultados mostram que o hambúrguer com adição de pulmão bovino pode ser considerado uma alternativa de utilização deste órgão bovino pouco consumido, além de ser promissor na dieta alimentar devido a sua quantidade de ferro. 
Figura 1 - Intenção de compra de hambúrgueres (A) sem a adição de pulmão - controle; (B) com 50 g de pulmão e (C) com $100 \mathrm{~g}$ de pulmão.

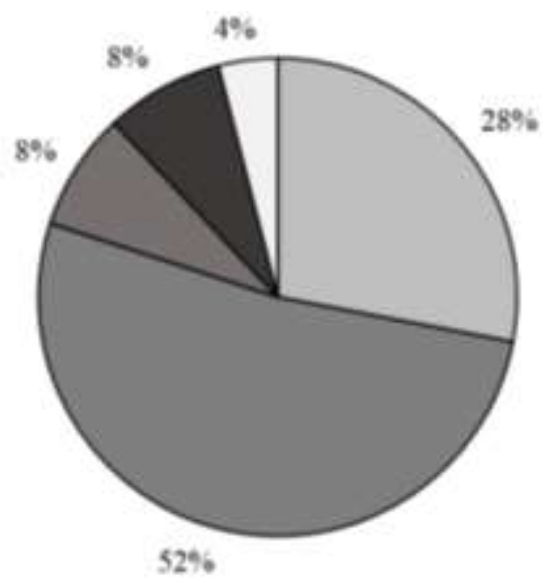

(A)
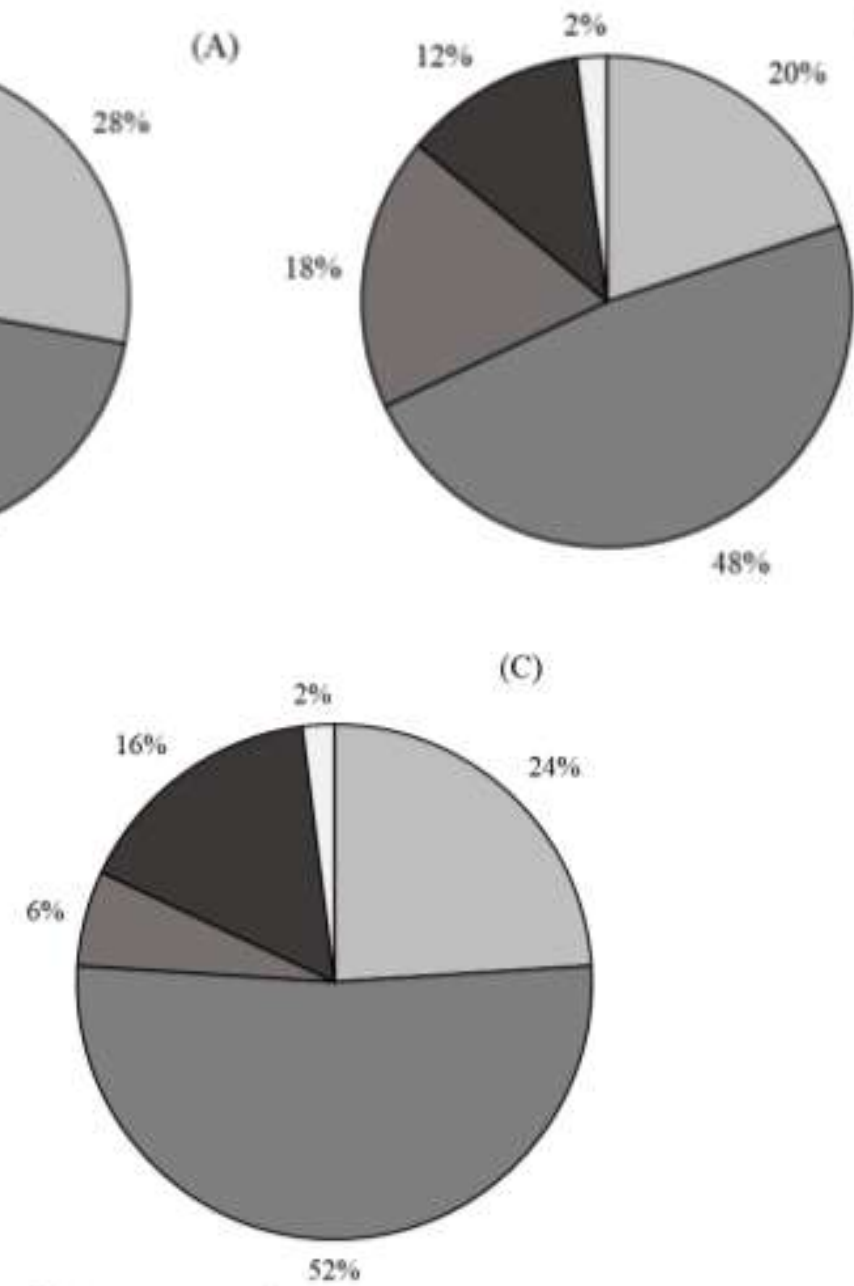

$$
\begin{aligned}
& \text { aCertamente compraria } \\
& \text { aProvavelmente compraria } \\
& \text { a Talvez compraria ou nåo compraria } \\
& \text { - Possivelmente nầo compraria } \\
& \text { aCertamente nâo compraria }
\end{aligned}
$$

Fonte: Dados da Pesquisa.

\section{Conclusão}

O hambúrguer formulado com diferentes quantidades de pulmão, apresentou como componentes majoritários: água, proteínas e lipídios. Observou-se um aumento significativo no teor de ferro nos produtos elaborados em comparação com amostra controle (sem a adição do pulmão), evidenciando que é possível obter um produto rico nutricionalmente, com baixo valor calórico através da adição do pulmão bovino à massa do hambúrguer. As formulações adicionadas de pulmão foram aceitas (IA>70\%) e apresentaram altas porcentagens de intenção de compra (>82\%). Desta forma, o pulmão bovino, considerado uma das partes menos nobres dos bovinos, torna-se uma fonte proteica alternativa de aproveitamento para a elaboração de novos produtos, além de contribuir para a redução da poluição do meio ambiente, evitando o descarte. Por este potencial, sugere-se outros estudos inserindo este subproduto em outros alimentos amplamente consumidos, como: embutidos e sopas em pó. 


\section{Referências}

Arueya, G. L., Owosen, B. S., \& Olatoye, K. K. (2017). Development of exturized vegetable protein from Lima bean (Phaseolus lunatus) and African oil bean seed pentaclethrama crophylla: optimization approach. Acta Universitatis Cibiniensis. Series E: Food Technology, 21 (1), 61-68.

Bezerra, A. G. N., Leal, V. S., Lira, P. I. C., Oliveira, J. S., Costa, E. C., Menezes, R. C. E., Campos, F. A. C. S. E. \& Andrade, M. I. S. (2018). Anemia and associated factors in women at reproductive age in a Brazilian Northeastern municipality. Revista Brasileira de Epidemiologia, $21,1-13$.

Bis-Souza, C. V., Henck, J. M. M. \& Barreto, A. C. S. (2018). Performance of low-fat beef burger with addition of soluble and insoluble dietary fibers. Food Science Tecnology, 38 (3), 522-529.

Borba, C. M., Oliveira, V. R., Venzke, J. G., Hertz, P. F. \& Montenegro, K.R. (2013). Physical and chemical quality of beef and chicken burgers submitted to different heat treatments. Alimentos e Nutrição, 24(1), 21-27.

Brasil. (1997). Ministério da Agricultura, Pecuária e Abastecimento. Regulamento da inspeção industrial e sanitária de produtos de origem animal. Diário Oficial da República Federativa do Brasil, Brasília, DF, 1997.

Brasil. (1998). Agência Nacional de Vigilância Sanitária. Portaria no. 1.004, de 11 de dezembro de 1998. Aprovar o Regulamento Técnico: "Atribuição de Aditivos, Aditivos e seus limites máximos de uso para a Categoria 8 - Carne e produtos cárneos. Diário Oficial da República Federativa do Brasil, Brasília, DF, 1998.

Brasil. (2002). Agência Nacional de Vigilância Sanitária. Resolução RDC nº 275, de 21 de outubro de 2002 . Dispõe sobre o Regulamento Técnico de Procedimentos Operacionias Padronizados aplicados aos estabelcimentos produtores/industrializadores de alimentos e a lista de verificaça das Boas Práticas de Fabricação em estabelecimentos produtores/industrializadores de alimentos. Diário Oficial da República Federativa do Brasil, Brasília,, DF, 2002.

Brasil. (2000). Ministério da Agricultura, Pecuária e Abastecimento. Instrução Normativa $n^{\circ}$ 31, de julho de 2000. Regulamentos Técnicos de Identidade e Qualidade de Almôndega, de apresuntado, de fiambre, de hambúrguer, de kibe, de presunto cozido e de presunto. Diário Oficial da República Federativa do Brasil, Brasília, DF, 2000.

Camaschella, C. (2017). New insights into iron deficiency and iron deficiency anemia. Blood Reviews, 31(4), 255-233.

Carmo, J. R., Costa, T. S. \& Pena, R. S. (2019) Tucupi-added mayonnaise: Characterization, sensorial evaluation, and rheological behavior. CyTA - Journal of Food, 17(1), 479-487.

Chadare, F. J., Idohou, R., Nago, E., Affonfere, M., Agossadou, J., Fassinou, T. K., Kénou, C., Honfo, S., Azokpota, P., Linnemann, A. R., \& Hounhouigan, D. J. (2019). Conventional and food-to-food fortification: An appraisal of past practices and lessons learned. Food Science and Nutrition, 7(9), 2781-2795.

Damasceno, G. A., Paixão, L. M. N., Oliveira, B. D. L., Barrozo, R. A., Goes, T. S., \& Silva, E. M. C. (2013). Estudo comparativo de cortes bovino: Avaliação nutricional e custo de filé mignom, músculo e pulmão bovino. In: Anais do Simpósio Latino Americano de Ciência dos Alimentos, Campinas.

Food and Agriculture Organization of the United Nations - FAO/WHO. (2002). Food and Agriculture Organization of the United Nations. Food energy: methods of analysis and conversion factors. Food and Nutrition. http://www.fao.org/uploads/media/FAO_2003_Food_Energy_02.pdf

Feiner, G. (2016). Salami: Practical Science and Processing Technology, 59-88.

Fernandes, A. B. C. \& Pizato, S. (2019). Elaboração de hambúrguer de carne bovina com adição de farinha de sorgo (Sorghum vulgare). Revista PubSaúde, $2(\mathrm{a} 009), 1-15$.

Grützmann, A., Zambalde, A. L. \& Bermejo, P. H. S. (2019). Inovação, Desenvolvimento de Novos Produtos e as Tecnologias Internet: estudo em empresas brasileiras. Gestão \& Produção, 26(1), 1-15.

Harika, R., Faber, M., Samuel, F., Mulugeta, A., Kimiywe, J. \& Eilander, A. (2017). Are Low Intakes and Deficiencies in Iron, Vitamin A, Zinc, and Iodine of Public Health Concern in Ethiopian, Kenyan, Nigerian, and South African Children and Adolescents? Food and Nutrition Bulletin, 38 , (3), $405-427$.

Hautrive, T. P., Piccolo, J., Rodrigues, A. S., Campagnol, P. C. B. \& Kubota, E. H. (2019). Effect of fat replacement by chitosan and golden flaxseed flour (whole and defatted) on the quality of hamburgers. LWT-Food Science and Techonology, 102, 403-410.

Hoffmann, S. A. \& Kruger, L. R. (2011). Elaboração, análise sensorial e físico-química de biscoito rico em ferro com farinha de pulmão bovino. Alimentos $e$ Nutrição, 22 (4), 577-583.

Instituto Adolfo Lutz - IAL. (2008). Normas Analíticas do Instituto Adolfo Lutz: Metodos físico-químicos para análises dos alimentos (4a ed.). IAL: São Paulo.

Institute of Medicine. (2001). Dietary reference intakes for vitamin a, vitamin k, arsenic, boron, chromium, copper, iodine, iron, manganese, molybdenum, nickel, silicon, vanadium and zinc. Washington: The National Academy Press.

Jayathilakan, K., Sultana, K., Radhakrishna, K. \& Bawa, A. S. (2012). Use of by-products and residues from the meat, poultry and fish processing industries: a review. Journal Food Science Technology, 49 (3), 278-293.

Lynch, S., Pfeiffer, C. M., Georgieff, M. K., Brittenham, G., Fairweather-Tait, S., Hurrell, F. R., Macardle, H. J. \& Raiten, D. J. (2018). Biomarkers of Nutrition for Development (BOND)-Iron review. Journal of Nutrition, 148, 1001S-1067S.

Magalhães, M. O., \& Cazal, M. M. (2021). Sensory analysis and brand influence on yogurt acceptance. Research, Society and Development, 10 (5), e55410515083.

Minim, V. P. R. (2013). Análise Sensorial: Estudos com consumidores (3a ed.). Editora UFV. 
Research, Society and Development, v. 10, n. 6, e59610616500, 2021

(CC BY 4.0) | ISSN 2525-3409 | DOI: http://dx.doi.org/10.33448/rsd-v10i6.16500

Moreira-Araújo, R. S. R., Araujo, M. A. M. \& Arêas, J. A. G. (2008). Fortified food made by the extrusion of a mixture of chickpea, corn and bovine lung controls iron-deficiency anaemia in preschool children. Food Chemistry, 107 (1), 158-164.

Organização Mundial de Saúde - OMS. (1975). Lucha contra la anemia nutricional, especialmente contra la carência de hierro: Informe ADI/OIEA/OMS. Série de Informes Técnicos, 580. Genebra.

Pasiakos, S. M., Agarwal, S., Lieberman, H. R. \& Fulgoni, V. L. (2015). Sources and amounts of animal, dairy, and plant protein intake of US adults in 20072010. Nutrients, 7 (8), 7058-7069.

Paula, M. M. O., Silva, J. R. G., Oliveira, K. L., Massingue, A. A., Ramos, E. M., Junior, A. A. B., Silva, M. H. L. \& Silva, V. R. O. (2019). Technological and sensory characteristics of hamburgers added with chia seed as fat replacer. Rural Science, 49 (8), e20190090.

Rocha, C. M. A., Machado, E. C. L., Machado, E. H. L., Ferreira, S. A. O. \& Andrade, S. A. C. (2019). Development of a hamburger-type product derived from bovine liver. Food Science and Technology, 39 (1), 158-162.

Rolim, C. D. (2015). Elaboração e avaliação de hambúrguer à base de carne bovina com teor reduzido de sódio. Trabalho de Conclusão de Curso (Graduação em Engenharia Agroindustrial), Universidade Federal do Rio Grande, Santo Antônio da Patrulha.

Lima Segundo, J. F., Jerônimo, H. M. Â., Viera, V. B., \& Nascimento, C. M. S. A. (2021). Desenvolvimento de hambúrguer vegano adicionado da farinha de couve folha: avaliação físico-química, microbiológica e sensorial. Research, Society and Development, 10 (1), e42510111761.

Selmane, D., Christophe, V. \& Gholamreza, D. (2008). Extraction of proteins from slaughterhouse by-products: Influence of operating conditions on functional properties. Meat Science, 79 (4), 640-647.

Silva, M. A., Carvalho, C. A., Fonseca, P. C. A., Vieira, S. A., Ribeiro, A. Q., Priore, S. E. \& Fransceschini, S. C. C. (2015). Prevalência e fatores associados à anemia ferropriva e hipovitaminose A em crianças menores de um ano. Cadernos Saúde Coletiva, 23(4), 362 -367.

Sobrinho, S. S., Gonçalves, C. A. A., Silva, M. B. B. L., Matos, M. M. S., Passos, L. D., Paiva, E. S. A., Pereira, L. A. \& Santos, A. C. R. (2009). Efeito do adição de vísceras na aceitação do hambúrguer de carne bovina produzido no setor de agroindústria do IF - Triângulo Mineiro. II Seminário de Iniciação Científica - IFTM, Campus Uberaba, 48-51.

Suman, S. P., \& Joseph, P. (2013). Myoglobin chemistry and meat color. Annual Review of Food Science and Technology, 4(1), 79-99.

Tabela Brasileira de Composição dos Alimentos - TACO. (2011). Campinas: NEPA-UNICAMP.

Vieira, D. A. D. S., Steluti, J., Jr, V. E., Marchioni, D. M., \& Fisberg, R. M. (2017). Brazilians' experiences with iron fortification: Evidence of effectiveness for reducing inadequate iron intakes with fortified flour policy. Public Health Nutrition, 20 (2), 363-370.

Wong, C. (2017). Iron deficiency anaemia. Paediatrics and Child Health (United Kingdom), 27 (11), 527-529.

Wyness, L. (2016). The role of red meat in the diet: Nutrition and health benefits. Proceedings of the Nutrition Society, 75 (3), $227-232$.

Yu, Q. P., Feng, D. Y., Xiao, J., Wu, F., He, X, J., Xia, M. H., Dong, T., Liu, Y. H., Tan, H. Z., Zou, S. G., Zheng, T., Ou, X. H. \& Zuo, J. J. (2017). Studies on meat color, myoglobin content, enzyme activities, and genes associated with oxidative potential of pigs slaughtered at different growth stages. AsianAustralasian Journal of Animal Sciences, 30(12), 1739-1750. 